\title{
Real-World Costs of Adverse Events in First-Line Treatment of Metastatic Non-Small Cell Lung Cancer
}

\author{
Nicole M. Engel-Nitz, PhD; Michael P. Johnson, MS; Scott H. Bunner, MPH; and Kellie J. Ryan, MPH
}

\begin{abstract}
BACKGROUND: Non-small cell lung cancer (NSCLC) is the most common form of lung cancer in the United States. Immunotherapies and cytotoxic chemotherapies used to treat advanced NSCLC carry a substantial risk of adverse events (AEs), but real-world data on the incidence and costs associated with the unique $A E$ profiles of these treatments are sparse.
\end{abstract}

OBJECTIVE: To examine the AE incidence and costs among patients initiating non-driver mutation-targeted first-line therapy for metastatic NSCLC (mNSCLC) in clinical practice.

METHODS: This was a retrospective administrative claims study conducted among commercial and Medicare Advantage health plan members who initiated first-line, nontargeted systemic anti-NSCLC therapy between January 1, 2008, and February 28, 2018. Patients were assigned to mutually exclusive treatment cohorts (cytotoxic chemotherapy [CHEM], immunooncology agents [10], or immuno-oncology + cytotoxic chemotherapy [I0-CHEM]) and were observed from the index date (start of first-line therapy) through the earliest of health plan disenrollment, death, or March 31,2018 . AE incidence rates and associated health care costs were measured from the index date through the earliest of the start of a new therapy, 180 days after the end of first-line therapy, or the end of the study period. The factors influencing whether patients incurred high AE-related health care costs were assessed using multivariable models adjusted for patient demographic and clinical characteristics.

RESULTS: The final study population (mean [SD] age 68.6 [9.5] years, $53.9 \%$ male) included 8,818 in the CHEM cohort, 482 in the 10 cohort, and 412 in the I0-CHEM cohort. Overall, $74.4 \%$ had at least 1 AE during followup. The $A E$ incidence rate was lowest for the 10 cohort, with incidence rate ratios $(95 \% \mathrm{Cl})$ of $1.4(1.3-1.6)$ for the CHEM cohort and 1.4 (1.2-1.6) for the I0-CHEM cohort. Mean AE-related costs were lowest for the I0 cohort $(\$ 16,319)$ and highest for the CHEM cohort $(\$ 23,009 ; P<0.001)$. In the multivariable analysis, the odds of incurring any $A E$ costs were similar for the 10 and I0-CHEM cohorts compared with the CHEM cohort $(\mathrm{OR}=0.82$; $P=0.135$ and $\mathrm{OR}=0.98 ; P=0.888$, respectively). Among patients who incurred $A E$ costs, those in the 10 cohort were less likely than those in the CHEM cohort to have high costs $(0 \mathrm{R}=0.60 ; P=0.030)$; the difference between the I0-CHEM and CHEM cohorts was not statistically significant.

CONCLUSIONS: Among real-world patients initiating nontargeted first-line therapy for mNSCLC, those receiving immunotherapy experienced fewer AEs and had lower total AE-related costs than those treated with cytotoxic chemotherapy. Immunotherapy-treated patients were no more likely than chemotherapy-treated patients to incur AE-related costs and were less likely to have high AE costs if they incurred any at all. These findings indicate that immunotherapy-related AEs are not a differentiating factor in cost of care for this patient population in clinical practice.

J Manag Care Spec Pharm. 2020;26(6):729-40

Copyright $\odot 2020$, Academy of Managed Care Pharmacy. All rights reserved.

\section{What is already known about this subject}

Immunotherapies and cytotoxic chemotherapies used to treat metastatic non-small cell lung cancer (mNSCLC) are associated with improved survival but also carry a substantial risk of adverse events (AEs).

Real-world data on the AE incidence and AE-related costs of current $\mathrm{mNSCLC}$ treatments are sparse.

\section{What this study adds}

Patients with first-line immunotherapy-treated mNSCLC had less frequent AEs, lower total AE costs, and lower odds of incurring high AE costs than those treated with cytotoxic chemotherapy. Patients with previous infections or neurological disorders had a higher likelihood of incurring high $\mathrm{AE}$ costs during first-line therapy.

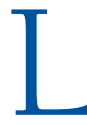
ung cancer is the leading cause of cancer mortality in the United States, with an estimated 228,150 new diagnoses and 142,670 deaths in 2019. ${ }^{1}$ It is also among the costliest cancers; total expenditures associated with lung cancer care in 2018 were estimated at more than $\$ 14$ billion nationally, and the total cost of treatment has been found to surpass $\$ 100,000$ per patient. ${ }^{2,3}$

Surgical resection is potentially curative for localized nonsmall cell lung cancer (NSCLC); however, $40 \%$ of patients with NSCLC already have stage IV disease at diagnosis. ${ }^{4}$ While platinum-based chemotherapy was long the primary option for first-line treatment of advanced NSCLC, the arsenal of available treatments expanded substantially with the development of drugs targeted toward specific driver mutations or the programmed cell death receptor-1 (PD-1) and programmed cell death-ligand 1 (PD-L1) pathways. ${ }^{5}$ Today, NSCLC treatment options for patients with metastatic tumors overexpressing PD-Ll and without driver mutations include not only traditional cytotoxic chemotherapy but also immunotherapy with immune checkpoint inhibitors such as pembrolizumab, nivolumab, and atezolizumab. ${ }^{6}$

Although current first-line therapies for advanced NSCLC are associated with improved survival, they also carry a substantial risk of adverse events (AEs). ${ }^{7}$ Immunotherapies are associated with lower rates of some toxicities common to classical chemotherapy, ${ }^{8-11}$ but they may cause unique 
immune-related AEs that can be severe and affect multiple organ systems, sometimes requiring hospitalization and/or treatment with steroids. ${ }^{12}$ While it is recognized that AEs of NSCLC treatment can reduce quality of life, ${ }^{13}$ real-world data on the incidence and costs associated with the unique AE profiles of these therapies are sparse. Much of our understanding about the extent of AEs experienced by patients treated for advanced NSCLC comes from clinical trials, ${ }^{14}$ which use highly selected patient samples that may differ substantially from realworld patient populations. ${ }^{15}$ Cost studies conducted among real-world patients with NSCLC have shown a high economic burden but did not differentiate between immunotherapy and conventional chemotherapy, ${ }^{16}$ did not specifically examine AE-related costs, ${ }^{3}$ or use data collected before the approval of first-line immunotherapy. ${ }^{17,18}$ The present study was conducted to address these knowledge gaps by examining the incidence and costs associated with selected AEs among patients initiating nontargeted first-line chemotherapy or immunotherapy for metastatic NSCLC (mNSCLC) in clinical practice.

\section{Methods}

\section{Study Design and Data Sources}

This was a retrospective study conducted using commercial and Medicare Advantage administrative claims data from the Optum Research Database (ORD) from January 1, 2007, through March 31, 2018 (study period). Mortality information was sourced from claims and Social Security Administration data as available. The ORD is geographically diverse across the United States and contains deidentified medical and pharmacy claims data and linked member enrollment information. Medical claims include diagnosis and procedure codes from the International Classification of Diseases, Ninth/ Tenth Revision, Clinical Modification (ICD-9/10-CM); Current Procedural Terminology or Healthcare Common Procedure Coding System codes; site of service codes; and paid amounts. Pharmacy claims include drug name, National Drug Code number, dosage form, drug strength, fill date, number of days supply, and financial information for outpatient pharmacy services. Because no identifiable protected health information was accessed in the conduct of this study, institutional review board approval or waiver of approval was not required.

\section{Patient Selection and Observation Periods}

The study included patients from the ORD with evidence of NSCLC who initiated first-line, non-driver mutationtargeted systemic anticancer therapy between January 1 , 2008, and February 28, 2018 (identification period). Inclusion criteria were at least 1 claim for National Comprehensive Cancer Network (NCCN)-recommended, nontargeted therapy for NSCLC (based on September 2017 guidelines) during the identification period (cisplatin, carboplatin, gemcitabine, pemetrexed, docetaxel, paclitaxel, etoposide, vinorelbine, vinblastine, bevacizumab, atezolizumab, nivolumab, pembrolizumab, and ramucirumab) ${ }^{19}$; continuous health plan enrollment with medical and pharmacy benefits for at least 6 months before and at least 1 month after the first qualifying claim for NSCLC therapy (index date); aged $\geq 18$ years as of the index date; at least 1 nondiagnostic claim for lung cancer (ICD-9-CM 162.xx or ICD-10-CM C34.xx) in the 6 months before the index date (6-month baseline period); and evidence of metastasis or unresectable locally advanced disease (at least 1 nondiagnostic claim for metastatic disease during the 6-month baseline period or within 30 days after the index date, or evidence of concurrent chemoradiation between 7 days before and up to 30 days after the index date). The period of continuous enrollment before the index date back to January 1, 2007, was the variable baseline period. The period of continuous enrollment from the index date through the earliest of health plan disenrollment, death, or March 31, 2018, was the follow-up period. At least 1 month of follow-up was required unless the patient had died.

Patients were excluded if they had evidence of lung cancerspecific surgery (not including biopsy) during the 6-month baseline period, any claim for systemic anticancer therapy (not including hormone therapies or radiopharmaceutical therapies) during the period 12 months before the index date, any claim for targeted therapy (Figure 1 footnote a) during the variable baseline period or follow-up period, 2 or more nondiagnostic claims at least 30 days apart with diagnosis codes for other cancers in position 1 or 2 during the variable baseline period, or any claim for drugs associated primarily with small cell lung cancer (Figure 1 footnote b) during the variable baseline period or follow-up period.

\section{Cohort Assignments and Line of Therapy Definitions}

Patients were assigned to mutually exclusive treatment cohorts (cytotoxic chemotherapy [CHEM], immuno-oncology agents [IO], or immuno-oncology + cytotoxic chemotherapy [IO-CHEM]) based on the first observed line of therapy (LOT), which by definition began on the index date (date of the first infusion or fill for a systemic anticancer agent). The first LOT included all agents received within 30 days following the index date and ended on the earliest of any of the following: addition or substitution of a new agent, treatment gap of at least 60 days after the run-out date of all agents in the LOT, death, health plan disenrollment, or end of the study period.

\section{Study Measures}

Patient demographic characteristics were assessed as of the index date. Baseline Quan-Charlson Comorbidity Index scores were assessed during the 6-month baseline period. ${ }^{20}$ Study outcomes were assessed during the follow-up period.

Selected AEs were measured during the AE observation period, which began on the index date (start of LOTl) and 
Commercially insured or Medicare Advantage patients with $\geq 1$ claim for NCCN-recommended therapy for NSCLC from January 1, 2008, to March 31, 2018 (identification period) $n=273,860$

Continuously enrolled patients with medical and pharmacy benefits for $\geq 6$ months before and $\geq 1$ month after index date (baseline and follow-up periods); aged $\geq 18$ years as of index date $n=197,358$

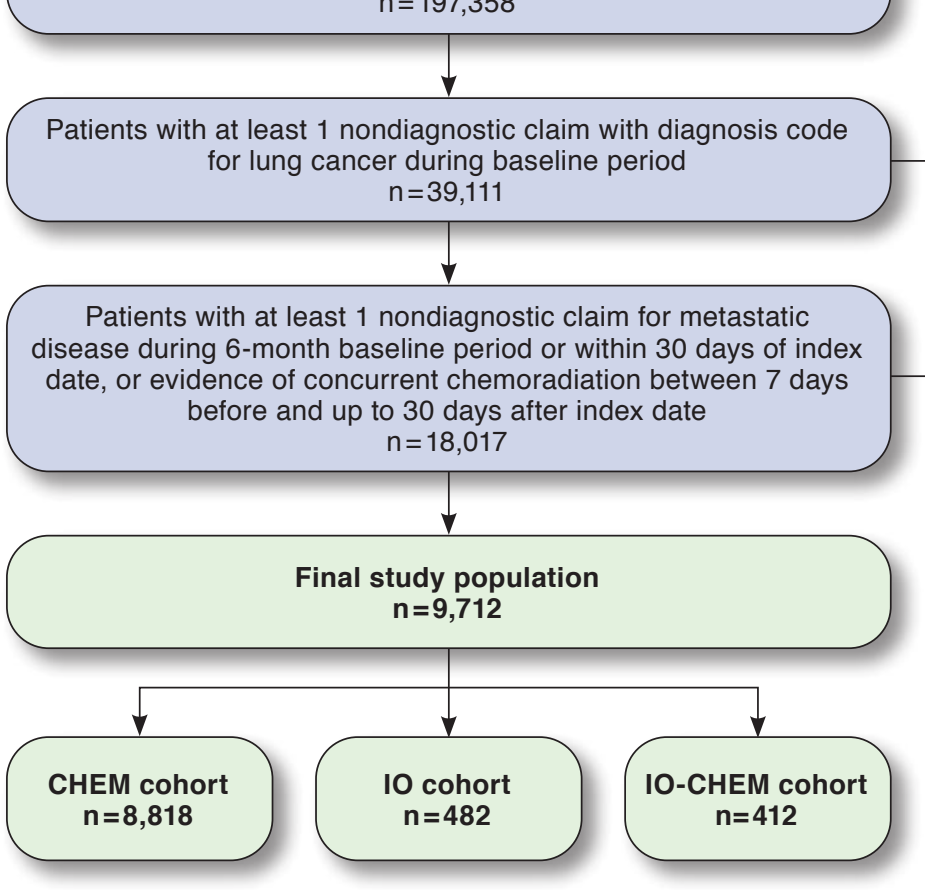

\section{Exclusions:}

- No continuous enrollment during specified periods $(n=76,212)$ - Aged $<18$ years as of index date $(n=290)$

- No evidence of lung cancer $(n=158,247)$

Exclusions:

- No evidence of radiation therapy or concurrent chemoradiation $(n=21,094)$

\section{Exclusions:}

- Evidence of lung cancer-specific surgery during 6-month baseline period $(n=2,037)$

- At least 1 claim for anticancer systematic therapy during 12 months before index date $(n=2,503)$

- At least 1 claim for driver mutation-targeted therapy during 12 months before index date $(n=1,174)^{a}$

- At least 1 claim for drugs associated with small cell lung cancer during baseline or follow-up periods $(n=772)^{\mathrm{b}}$

- At least 2 nondiagnostic claims with diagnosis codes for other cancers at least 30 days apart during 6 months before index date $(n=1,819)$

aAfatinib, alectinib, brigatinib, crizotinib, ceritinib, erlotinib, gefitinib, trastuzumab,vandetanib, cabozantinib, ado-trastuzumab emtansine, dasatinib, imbrutinib, vemarafenib, osimertinib, dabrafenib, trametinib, and cetuximab.

${ }^{b}$ Topotecan, temozolomide, cyclophosphamide, doxorubicin, vincristine, and bendamustine.

CHEM = cytotoxic chemotherapy; IO=immuno-oncology agents = IO-CHEM, immuno-oncology +cytotoxic chemotherapy; NCCN = National Comprehensive Cancer Network; NSCLC=non-small cell lung cancer.

ended on the earliest of the start of a new LOT; 180 days after the end of LOTl; or at the end of the study period. AEs measured in this study included those with a prevalence of at least $10 \%$ according to the drug labels for NCCN-recommended therapies and some AEs that were less prevalent but were selected by a clinical expert because of severity and/or clinical relevance to immunotherapy. AEs other than infusion reactions were identified on the basis of claims with a relevant ICD-9/10-CM diagnosis code in position 1 or 2 or a relevant procedure code on a medical claim. Infusion reactions were identified on the basis of codes for specified conditions (hypertension, hypertensive crises associated with neurological signs and symptoms, wheezing, oxygen desaturation, chest pain, headaches, rigors, hypotension, and diaphoresis) occurring in position 1 or 2 on claims within 2 days of an infusion (defined as the dates of medical claims for chemotherapy or immunotherapy during the LOT). Conditions were not considered as infusion reactions if the patient had a claim with a diagnosis for that condition in the 7 days before the infusion. Blood disorders (anemia, thrombocytopenia, leukopenia) 


\begin{tabular}{|c|c|c|c|c|c|c|c|c|c|c|}
\hline \multirow{3}{*}{$\begin{array}{l}\text { Characteristic } \\
\text { Age, years, mean (SD) }\end{array}$} & \multirow{2}{*}{\multicolumn{2}{|c|}{$\begin{array}{c}\text { Total } \\
(\mathrm{N}=9,712)\end{array}$}} & \multirow{2}{*}{\multicolumn{2}{|c|}{$\begin{array}{c}\text { CHEM } \\
(\mathbf{n}=8,818)\end{array}$}} & \multirow{2}{*}{\multicolumn{2}{|c|}{$\begin{array}{c}\mathrm{IO} \\
(\mathrm{n}=482)\end{array}$}} & \multirow{2}{*}{\multicolumn{2}{|c|}{$\begin{array}{c}\text { IO-CHEM } \\
(n=412)\end{array}$}} & \multicolumn{2}{|c|}{$P$ Value } \\
\hline & & & & & & & & & \multirow{2}{*}{$\begin{array}{l}\begin{array}{l}\text { CHEM } \\
\text { vs. IO }\end{array} \\
<0.001\end{array}$} & \multirow{2}{*}{$\begin{array}{c}\text { IO-CHEM } \\
\text { vs. IO } \\
<0.001\end{array}$} \\
\hline & 68.6 & $(9.5)$ & 68.4 & (9.4) & 72.2 & $(9.9)$ & 69.5 & $(9.5)$ & & \\
\hline Follow-up time, months, mean (SD) & 163.7 & $(122.5)$ & 164.3 & $(122.2)$ & 173.4 & $(142.3)$ & 139.3 & $(100.9)$ & 0.170 & $<0.001$ \\
\hline \multicolumn{11}{|l|}{ Baseline CCI score category, $\mathbf{n}(\%)$} \\
\hline $1-2$ & 163 & (1.7) & 147 & $(1.7)$ & 12 & $(2.5)$ & 4 & (1.0) & 0.175 & 0.088 \\
\hline $3-4$ & 401 & $(4.1)$ & 373 & $(4.2)$ & 16 & (3.3) & 12 & $(2.9)$ & 0.331 & 0.728 \\
\hline $5+$ & 9,148 & $(94.2)$ & 8,298 & $(94.1)$ & 454 & $(94.2)$ & 396 & $(96.1)$ & 0.936 & 0.185 \\
\hline Sex, male, n (\%) & 5,239 & $(53.9)$ & 4,795 & $(54.4)$ & 225 & $(46.7)$ & 219 & $(53.2)$ & $<0.001$ & 0.054 \\
\hline \multicolumn{9}{|l|}{ Insurance type, n (\%) } & $<0.001$ & 0.001 \\
\hline Commercial & 3,469 & (35.7) & 3,267 & $(37.1)$ & 89 & $(18.5)$ & 113 & $(27.4)$ & & \\
\hline Medicare Advantage & 6,243 & $(64.3)$ & 5,551 & $(63.0)$ & 393 & $(81.5)$ & 299 & $(72.6)$ & & \\
\hline \multicolumn{9}{|l|}{ Geographic region } & 0.222 & 0.470 \\
\hline Northeast & 1,514 & (15.6) & 1,364 & $(15.5)$ & 87 & $(18.1)$ & 63 & (15.3) & & \\
\hline Midwest & 3,265 & $(33.6)$ & 2,966 & $(33.6)$ & 156 & $(32.4)$ & 143 & $(34.7)$ & & \\
\hline South & 4,058 & $(41.8)$ & 3,684 & (41.8) & 205 & $(42.5)$ & 169 & $(41.0)$ & & \\
\hline West & 875 & $(9.0)$ & 804 & $(9.1)$ & 34 & $(7.1)$ & 37 & (9.0) & & \\
\hline
\end{tabular}

CCI=Charlson Comorbidity Index; CHEM = cytotoxic chemotherapy; IO=immuno-oncology agents; IO-CHEM =immuno-oncology+cytotoxic chemotherapy;

$S D=$ standard deviation.

were calculated separately as well as presented as a group. AE incidence was calculated only among patients without the selected AE during the variable baseline period. Incidence rates were calculated by dividing the number of patients with the $\mathrm{AE}$ during the AE observation period by the total patient-years of observation up to the occurrence of the AE.

Health care costs associated with selected AEs were calculated as the combined health plan-paid amounts plus patientpaid amounts during the AE observation period, adjusted to 2017 U.S. dollars using the annual medical care component of the Consumer Price Index. ${ }^{21}$ Total costs for each AE were calculated as the sum of costs on each claim associated with the $\mathrm{AE}$. For claims that contained codes for more than $1 \mathrm{AE}$, costs were attributed separately to the total costs of each AE. For AE costs associated with inpatient stays, the costs of the entire stay were attributed to the AE. Pharmacy costs associated with each AE were calculated on the basis of all pharmacy claims with dates between the first and last medical claims associated with the AE. In addition to total AE costs over the AE period, population-level per patient per month (PPPM) costs were estimated.

\section{Statistical Analysis}

Analytic dataset creation was conducted using SAS software version 9.4 (SAS Institute, Cary, NC). All study variables were analyzed descriptively. Results were stratified by treatment cohort and compared using statistical tests appropriate for the distribution of the measure (e.g., t-test, Mann-Whitney U-test, chi-square test). Incidence rate ratios (IRRs) were calculated to compare the risks of selected AEs among treatment cohorts; chi-square testing was performed, with 95\% confidence intervals (CIs) derived using 10,000 bootstrapped samples for the composite measures of any AE and blood condition, and standard binomial CIs for the remaining AEs. $P$ values $\leq 0.05$ were considered to indicate statistical significance.

The factors influencing whether patients had high AE-related health care costs were assessed using logistic regressions adjusted for insurance type, geographic region, sex, baseline Charlson score, baseline metastatic disease, and baseline AEs. Because a substantial number of patients had zero AE costs, 1 model estimated the probability of incurring any AE cost, and a separate model estimated the probability of having high costs (defined as the 90th percentile) among patients incurring $>\$ 0 \mathrm{AE}$ costs. ${ }^{22}$ Odds ratios (ORs), 95\% CIs, and $P$ values are presented for each covariate included in the logistic models.

\section{Results}

\section{Patient Characteristics}

Of 273,860 patients with at least 1 claim for nontargeted, NCCN-recommended therapy for NSCLC during the identification period, 9,712 met the remaining study criteria (Figure 1). The final study population included 8,818 in the CHEM cohort, 482 in the IO cohort, and 412 in the IO-CHEM cohort. In the total population, mean (standard deviation; SD) age was 68.6 (9.5) years, 53.9\% were male, and 64.3\% had Medicare Advantage insurance. Most patients (94.2\%) had a baseline Charlson comorbidity score of 5 or more (Table 1).

Patient characteristics were similar among the 3 cohorts, with a few exceptions (Table 1). The IO cohort had a higher mean age compared with the CHEM and IO-CHEM cohorts 
Real-World Costs of Adverse Events in First-Line Treatment of Metastatic Non-Small Cell Lung Cancer

TABLE 2 Incidence Rates of Selected AEs During the AE Period

\begin{tabular}{|c|c|c|c|c|c|c|c|}
\hline \multirow[b]{2}{*}{ Event } & \multicolumn{4}{|c|}{ Incidence Rate ${ }^{a}$ per 1,000 Person-Years } & \multicolumn{3}{|c|}{ Incidence Rate Ratio $(95 \% \mathrm{CI})^{\mathrm{b}}$} \\
\hline & $\begin{array}{c}\text { Total } \\
(\mathrm{N}=9,712) \\
\end{array}$ & $\begin{array}{c}\text { CHEM } \\
(\mathbf{n}=8,818)\end{array}$ & $\begin{array}{c}\text { IO } \\
(n=482)\end{array}$ & $\begin{array}{c}\text { IO-CHEM } \\
(n=412)\end{array}$ & CHEM vs. IO & $\mathrm{IO}-\mathrm{C}$ & HEM vs. IO \\
\hline Any selected $\mathrm{AE}$ & 9,135 & 9,327 & 6,499 & 8,843 & $1.4 \quad(1.2-1.7)$ & 1.4 & $(1.1-1.7)$ \\
\hline Blood disorders & 1,403 & 1,527 & 327 & 806 & $4.7 \quad(3.5-6.0)$ & 2.5 & $(1.7-3.5)$ \\
\hline Anemia & 774 & 826 & 145 & 589 & $5.7 \quad(4.0-8.4)$ & 4.1 & $(2.6-6.4)$ \\
\hline Infusion reactions & 767 & 752 & 842 & 1,051 & $0.9 \quad(0.8-1.1)$ & 1.2 & $(0.9-1.7)$ \\
\hline Gastrointestinal disorders & 922 & 952 & 501 & 854 & $1.9 \quad(1.5-2.4)$ & 1.7 & $(1.3-2.3)$ \\
\hline Infections & 761 & 811 & 417 & 505 & $1.9 \quad(1.6-2.5)$ & 1.2 & $(0.9-1.7)$ \\
\hline Leukopenia & 448 & 493 & 22 & 126 & $22.3 \quad(9.5-68.7)$ & 5.7 & $(2.1-19.5)$ \\
\hline Neurological disorders & 305 & 308 & 259 & 283 & $1.2 \quad(0.9-1.6)$ & 1.1 & $(0.7-1.7)$ \\
\hline Hemorrhage & 253 & 260 & 195 & 175 & $1.3 \quad(0.97-1.9)$ & 0.9 & $(0.5-1.5)$ \\
\hline Kidney injury & 208 & 209 & 186 & 233 & $1.1 \quad(0.8-1.6)$ & 1.3 & $(0.8-2.1)$ \\
\hline Thrombocytopenia & 140 & 149 & 40 & 81 & $3.7 \quad(1.9-8.1)$ & 2.0 & $(0.8-5.4)$ \\
\hline Hypothyroidism & 70 & 55 & 284 & 180 & $0.2 \quad(0.1-0.3)$ & 0.6 & $(0.4-1.1)$ \\
\hline Pneumonitis & 55 & 53 & 70 & 75 & $0.8 \quad(0.5-1.4)$ & 1.1 & $(0.5-2.5)$ \\
\hline Ocular disorders & 32 & 32 & 32 & 26 & $1.0 \quad(0.5-2.6)$ & 0.8 & $(0.2-3.2)$ \\
\hline Hepatitis & 21 & 23 & 4 & 6 & $5.1 \quad(0.9-204.2)$ & 1.5 & $(0.0-114.8)$ \\
\hline Type 1 diabetes & 17 & 18 & 14 & 20 & $1.3 \quad(0.4-6.5)$ & 1.5 & $(0.2-11.2)$ \\
\hline Myositis & 15 & 16 & 4 & 0 & $3.7 \quad(0.6-147.5)$ & 0.0 & $(0.0-56.8)$ \\
\hline Hyperthyroidism & 8 & 6 & 36 & 33 & $\begin{array}{ll}0.2 & (0.1-0.4) \\
\end{array}$ & 0.9 & $(0.2-3.2)$ \\
\hline
\end{tabular}

(72.2 years vs. 68.4 years and 69.5 years, respectively; $P<0.001$ for both) and a higher percentage of patients with Medicare Advantage insurance $(81.5 \%$ vs. $63.0 \%$ and $72.6 \%$, respectively; $\mathrm{P}<0.001$ for CHEM vs. IO; $P=0.001$ for IO-CHEM vs. IO). In addition, the IO cohort had a shorter follow-up time compared with the IO cohort (139.3 days vs. 173.4 days; $P<0.001)$ and a lower percentage of men compared with the CHEM cohort (46.7\% vs. 54.4\%; $P<0.001)$.

Among NCCN-recommended agents, the most common cytotoxic chemotherapies (used by $>10 \%$ of patients) were carboplatin (73.7\%), pemetrexed (29.7\%), paclitaxel (22.4\%), etoposide (22.2\%), and bevacizumab (11.5\%). The prevalence of immuno-oncology agent use (as monotherapy or part of combination therapy) was $6.9 \%$ for pembrolizumab, $1.5 \%$ for nivolumab, and $0.1 \%$ for atezolizumab.

\section{Incidence of Selected Adverse Events}

$\mathrm{AE}$ incidence during the $\mathrm{AE}$ observation period is presented for patients who did not have evidence of that AE during the baseline period. Overall, $74.4 \%$ of the study population had $\geq 1$ AE during follow-up (Appendix A, available in online article); compared with the IO cohort, IRRs (95\% CI) were 1.4 (1.2-1.7) for the CHEM cohort and 1.4 (1.1-1.7) for the IO-CHEM cohort (Table 2). Common AEs across all treatment cohorts in the total study population included blood disorders (43.0\%), gastrointestinal (GI) disorders (31.6\%), and infections (28.5\%; Appendix A). IRRs that were significantly higher for the other cohorts compared with the IO cohort included anemia (IRR = 5.7 CHEM, IRR=4.1 IO-CHEM), GI disorders (IRR=1.9 CHEM, IRR = 1.7 IO-CHEM), leukopenia $($ IRR = 22.3 CHEM, IRR=5.7 IO-CHEM), and thrombocytopenia (IRR=3.7 CHEM). The CHEM cohort had lower rates versus the IO cohort for hypothyroidism (IRR=0.2 CHEM) and hyperthyroidism (IRR=0.2 CHEM; Table 2).

\section{Health Care Costs Related to Adverse Events}

Total cost of AEs varied across the cohorts: mean AE-related costs were highest for the CHEM cohort $(\$ 23,009)$ and lowest for the IO cohort $(\$ 16,319 ; P<0.001$; Figure 2). Although the mean cost for the IO-CHEM cohort $(\$ 18,806)$ was higher than that for the IO cohort, the difference was not statistically significant. When examined as a PPPM measure, total AE-related costs were significantly lower for the IO cohort $(\$ 4,259)$ compared with the CHEM cohort $(\$ 6,323 ; P<0.001)$ or the IO-CHEM cohort $(\$ 6,269 ; P=0.020)$. With a few exceptions, the mean cost per patient for a specific AE (among patients with that AE during follow-up but not in the baseline period) did not differ across the systemic therapy cohorts, whether measured as a total cost or as a PPPM cost across the AE period (Figure 2 and Appendix B, available in online article). Mean AE costs were significantly higher for the CHEM cohort versus the IO cohort for blood disorders ( $\$ 16,922$ vs. $\$ 9,524 ; P<0.001)$, 


\section{FIGURE 2 Total AE-Related Health Care Costs Per Patient During the AE Period}

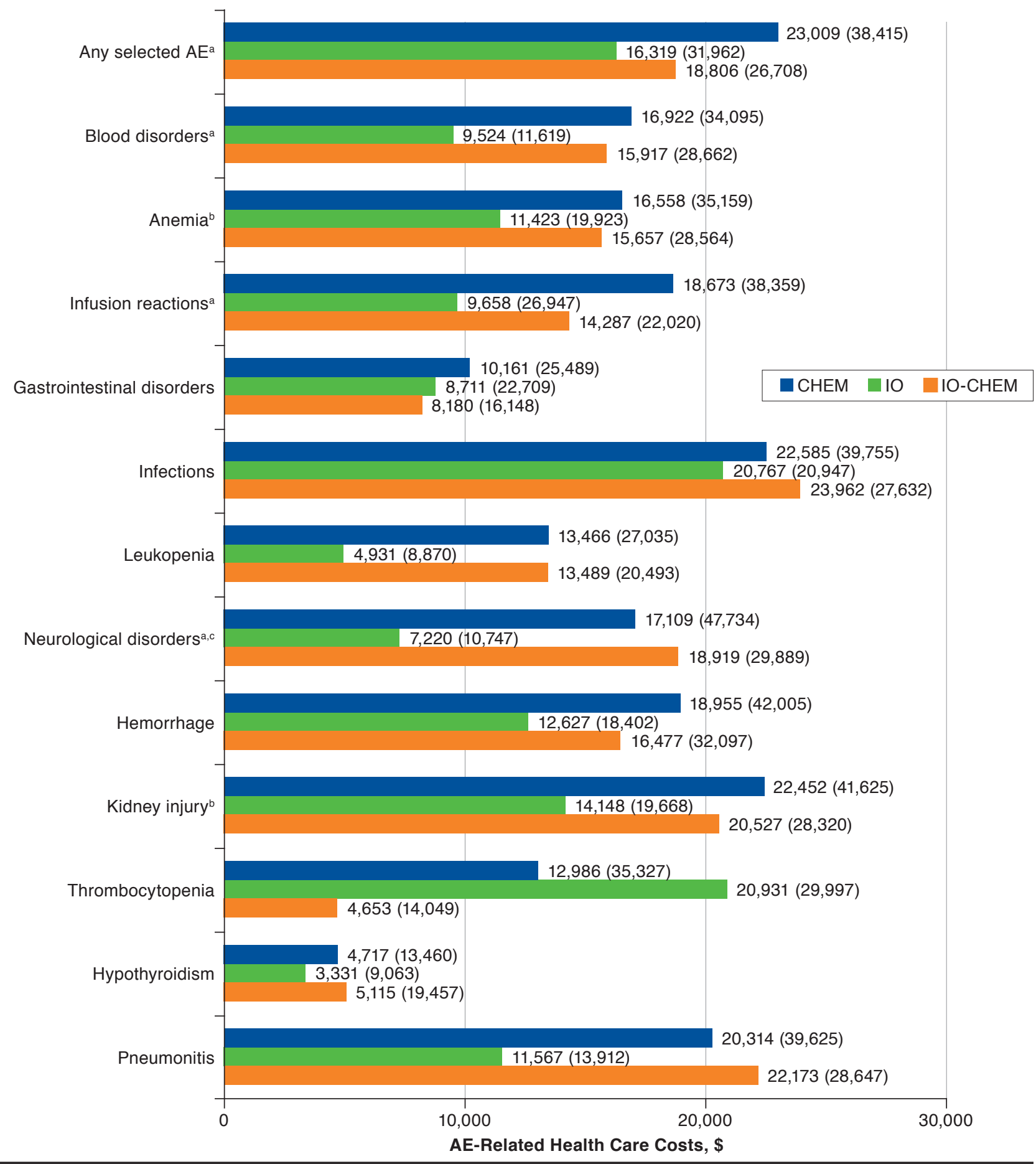

Note: AEs occurring in $>2 \%$ of patients are shown, listed in order of incidence rate from highest (any selected AE) to lowest (pneumonitis). Costs presented are among patients without the selected AE during the variable baseline period and exclude zero costs. AE-related health care costs are represented as mean (SD) in U.S. dollars. aP $<0.001$ for CHEM vs. IO

${ }^{b} \mathrm{P}<0.05$ for CHEM vs. IO.

${ }^{c} \mathrm{P}<0.05$ for IO-CHEM vs. IO.

$A E=$ adverse event CHEM = cytotoxic chemotherapy; IO=immuno-oncology agents; IO-CHEM=immuno-oncology +cytotoxic chemotherapy; $S D=$ standard deviation 


\section{TABLE 3 Logistic Models of AE-Related Costs}

\begin{tabular}{|c|c|c|c|c|c|c|}
\hline \multirow[b]{2}{*}{ Independent Variable } & \multicolumn{3}{|c|}{ Positive AE-Related Costs ${ }^{a}$} & \multicolumn{3}{|c|}{$\begin{array}{l}\text { High AE-Related Costs Among } \\
\text { Patients Incurring Any AE Costs }{ }^{\mathrm{b}, \mathrm{c}}\end{array}$} \\
\hline & Odds Ratio (95\% CI) & $P$ Value & Predicted Value & Odds Ratio (95\% CI) & $P$ Value & Predicted Value \\
\hline \multicolumn{7}{|l|}{ Cohort } \\
\hline CHEM & reference & - & 0.877 & reference & - & 0.102 \\
\hline IO & $0.82 \quad(0.63-1.06)$ & 0.135 & 0.854 & $0.60 \quad(0.38-0.95)$ & 0.030 & 0.065 \\
\hline IO-CHEM & $0.98 \quad(0.73-1.32)$ & 0.888 & 0.875 & $(0.51-1.20)$ & 0.263 & 0.083 \\
\hline \multicolumn{7}{|l|}{ Insurance type } \\
\hline Commercial & reference & - & & reference & - & \\
\hline Medicare Advantage & $1.32 \quad(1.16-1.50)$ & $<0.001$ & & $0.27 \quad(0.24-0.32)$ & $<0.001$ & \\
\hline \multicolumn{7}{|l|}{ Geographic region } \\
\hline Northeast & $1.17 \quad(0.97-1.42)$ & 0.097 & & $1.57 \quad(1.27-1.93)$ & $<0.001$ & \\
\hline Midwest & $1.05 \quad(0.91-1.20)$ & 0.521 & & $0.91 \quad(0.76-1.09)$ & 0.304 & \\
\hline South & reference & - & & reference & - & \\
\hline West & $1.10 \quad(0.88-1.38)$ & 0.391 & & $1.25 \quad(0.98-1.59)$ & 0.073 & \\
\hline \multicolumn{7}{|l|}{ Sex } \\
\hline Female & reference & - & & reference & - & \\
\hline Male & $1.00 \quad(0.88-1.13)$ & 0.996 & & $0.98 \quad(0.84-1.14)$ & 0.773 & \\
\hline \multicolumn{7}{|l|}{ Baseline CCI score category } \\
\hline $1-2$ & reference & - & & reference & - & \\
\hline $3-4$ & $1.03 \quad(0.57-1.86)$ & 0.932 & & $0.94 \quad(0.50-1.76)$ & 0.841 & \\
\hline $5+$ & $1.25 \quad(0.70-2.22)$ & 0.446 & & $1.35 \quad(0.75-2.41)$ & 0.315 & \\
\hline Baseline metastatic disease & $0.61 \quad(0.45-0.84)$ & 0.002 & & $0.62 \quad(0.47-0.82)$ & $<0.001$ & \\
\hline \multicolumn{7}{|l|}{ Baseline conditions } \\
\hline Gastrointestinal disorders & $0.92 \quad(0.78-1.09)$ & 0.330 & & $1.04 \quad(0.85-1.27)$ & 0.701 & \\
\hline Hepatitis & $1.06 \quad(0.60-1.86)$ & 0.848 & & $1.37 \quad(0.81-2.33)$ & 0.239 & \\
\hline Hyperthyroidism & $1.30 \quad(0.52-3.28)$ & 0.578 & & $1.01 \quad(0.39-2.61)$ & 0.987 & \\
\hline Hypothyroidism & $1.24 \quad(0.96-1.60)$ & 0.096 & & $0.95 \quad(0.71-1.28)$ & 0.736 & \\
\hline Infections & $1.40 \quad(1.22-1.60)$ & $<0.001$ & & $1.17 \quad(1.01-1.36)$ & 0.036 & \\
\hline Kidney injury & $1.51 \quad(1.17-1.95)$ & 0.001 & & $1.09 \quad(0.84-1.42)$ & 0.512 & \\
\hline Myositis & $1.92 \quad(1.11-3.33)$ & 0.020 & & $1.04 \quad(0.67-1.62)$ & 0.855 & \\
\hline Neurological disorders & $1.02 \quad(0.83-1.23)$ & 0.833 & & $1.51 \quad(1.21-1.89)$ & $<0.001$ & \\
\hline Ocular disorders & $1.58 \quad(0.89-2.81)$ & 0.118 & & $0.92 \quad(0.52-1.64)$ & 0.787 & \\
\hline Pneumonitis & $1.19 \quad(0.86-1.65)$ & 0.302 & & $1.13 \quad(0.81-1.59)$ & 0.474 & \\
\hline Type 1 diabetes & $1.74 \quad(0.94-3.23)$ & 0.080 & & $0.68 \quad(0.35-1.32)$ & 0.257 & \\
\hline Blood disorders & $1.13 \quad(0.95-1.33)$ & 0.160 & & $1.15 \quad(0.96-1.38)$ & 0.122 & \\
\hline
\end{tabular}

aLikelihood ratio: chi-square $=106.446, \mathrm{DF}=22, \mathrm{P}<0.001$.

${ }^{b}$ High AE-related costs are defined as those in the 90th percentile $(\geq \$ 49,402$ during the AE period).

CLikelihood ratio: chi-square $=371.467, \mathrm{DF}=22, \mathrm{P}<0.001$.

$A E=$ adverse event $C C I=$ Charlson Comorbidity Index; $C H E M=$ cytotoxic chemotherapy; $C I=$ confidence interval; $D F=$ degrees of freedom; $I O=$ immuno-oncology agents; IO-CHEM = immuno-oncology + cytotoxic chemotherapy.

anemia $(\$ 16,558$ vs. $\$ 11,423 ; P<0.05)$, infusion reactions $(\$ 18,673$ vs. $\$ 9,658 ; P<0.001)$, neurological disorders $(\$ 17,109$ vs. $\$ 7,220 ; P<0.001$ ), and kidney injury ( $\$ 22,452$ vs. $\$ 14,148$; $P<0.05$; Figure 2). Mean AE costs were significantly higher for the IO-CHEM cohort $(\$ 18,919)$ versus the IO cohort for neurological disorders $(P<0.05$; Figure 2$)$.

\section{Multivariable Analysis of AE-Related Costs and Descriptive Analysis of High-Cost and Lower-Cost Cohorts}

Patients with AE-related costs were stratified into high-cost (90th percentile, $\geq \$ 49,402 ; n=745)$ and lower-cost $(n=7,763)$ cohorts on the basis of total AE costs. Compared with the
CHEM cohort, the IO and IO-CHEM cohorts were not statistically significantly different in their odds of having any AE costs; the predicted proportions of patients incurring costs were $87.7 \%$ for the CHEM cohort, $85.4 \%$ for the IO cohort, and $87.5 \%$ for the IO-CHEM cohort (Table 3). However, the odds of having AE costs were higher for Medicare Advantage enrollees $(\mathrm{OR}=1.32 ; P<0.001)$ and patients with baseline infections $(\mathrm{OR}=1.40 ; \mathrm{P}<0.001)$, kidney injury $(\mathrm{OR}=1.51 ; P=0.001)$, or myositis $(\mathrm{OR}=1.92 ; P=0.020)$ and lower for those with a code for metastatic disease during the 6 -month baseline period $(\mathrm{OR}=0.61 ; P=0.002)$. 
Descriptive analysis of the high-cost versus lower-cost cohorts showed that patients in the high-cost cohort were slightly younger (mean age 64.8 years vs. 69.2 years; $P<0.001$ ), but there were no statistically significant differences in baseline Charlson comorbidity scores (mean 7.3 vs. $7.2 ; P=0.224$ ) or the percentage of patients with baseline metastatic disease ( $86.3 \%$ vs. $88.6 \% ; P=0.061$ ). A higher percentage of high-cost patients had inpatient stays ( $91.9 \%$ vs. $44.6 \% ; P<0.001)$, intensive care unit (ICU) admissions (37.1\% vs. 8.1\%; $P<0.001$ ), and emergency department (ED) visits (67.7\% vs. 55.8\%; $P<0.001)$ during the AE period. Mean (SD) follow-up time was longer for the high-cost cohort than the lower-cost cohort (196.3 [137.6] days vs. 167.7 [124.0] days). When prevalence rate ratios for high-cost versus lower-cost patients were examined to account for variable follow-up time, high-cost patients were found to have lower rates of ED visits (rate ratio $=0.84$, 95\% CI $=0.75-0.93$ ) and ICU admissions (rate ratio $=0.72,95 \%$ $\mathrm{CI}=0.62-0.83$ ), and the difference in rates of inpatient stays was not statistically significant (rate ratio $=1.02,95 \% \mathrm{CI}=0.94-1.12$ ).

Among patients who incurred AE-related costs, those in the IO cohort were less likely than those in the CHEM cohort to have high costs $(\mathrm{OR}=0.60,95 \% \mathrm{CI}=0.38-0.95 ; P=0.030$; Table 3), but the difference between the IO-CHEM and CHEM cohorts was not statistically significant. The predicted proportions of patients falling in the high-cost group were $10.2 \%$ for the CHEM cohort, $6.5 \%$ for the IO cohort, and $8.3 \%$ for the IO-CHEM cohort. Patients with AE-related costs were more likely to be in the high-cost group if they lived in the Northeast $(\mathrm{OR}=1.57,95 \% \mathrm{CI}=1.27-1.93 ; \mathrm{P}<0.001)$ or had baseline infections (OR=1.17, 95\% CI =1.01-1.36; $P=0.036)$ or neurological disorders $(\mathrm{OR}=1.51,95 \% \mathrm{CI}=1.21-1.89 ; \mathrm{P}<0.001)$, and were less likely to be in the high-cost group if they were Medicare Advantage enrollees $(\mathrm{OR}=0.27,95 \% \mathrm{CI}=0.24-0.32 ; \mathrm{P}<0.001)$ or had a code for metastatic disease during the baseline period $(\mathrm{OR}=0.62,95 \% \mathrm{CI}=0.47-0.82 ; \mathrm{P}<0.001)$.

\section{Discussion}

In this study of real-world patients initiating nontargeted firstline therapy for mNSCLC, AEs were less frequent and total AE costs were significantly lower for those treated with immunotherapy compared with those treated with cytotoxic chemotherapy either alone or in combination with immuno-oncology agents. While the odds of incurring any AE-related costs were similar among cohorts, patients in the IO cohort who had AE costs were less likely to have high costs compared with patients in the CHEM cohort. These findings suggest that IO-related AEs are not a substantial driver of cost of care during first-line treatment of mNSCLC.

AEs were common in this study population, with $74 \%$ of patients having at least 1 selected AE during the followup period. This prevalence is consistent with randomized clinical trials (RCTs). A meta-analysis of 7 RCTs including
2,122 patients with advanced NSCLC and 1,328 with advanced melanoma showed that the percentage experiencing any $\mathrm{AE}$ ranged from $67.6 \%$ for those treated with PD-1/PD-L1 inhibitors to $82.9 \%$ for those treated with conventional chemotherapy ${ }^{14}$ In addition, we found that AE incidence was 1.4 times higher among patients in the CHEM and IO-CHEM cohorts compared with the IO cohort. This is also congruent with RCTs, in which AE prevalence has consistently been lower among patients in immunotherapy arms compared with those in chemotherapy arms (relative risk $=0.82$ for any AE, according to the meta-analysis). ${ }^{14}$ As in RCTs, blood disorders, GI disorders, and neurological disorders in the present study were all significantly more common among patients receiving conventional chemotherapy, whereas patients receiving IO alone were more likely to experience immune-related AEs such as hypothyroidism, hyperthyroidism, and pneumonitis. ${ }^{14}$

Our study is the first to our knowledge to examine the unique AE profiles of both chemotherapy and immunotherapy treatment and their costs among real-world patients with mNSCLC. In another recent retrospective database study of patients with NSCLC treated with $\mathrm{PD}(\mathrm{L})-1$ inhibitors, Cathcart-Rake et al. (2018) noted that hypothyroidism and blood disorders were the most frequent AEs (9.2\% and 5.7\% prevalence, respectively). ${ }^{23}$ However, comparability with our results is limited, as the Cathcart-Rake study did not examine patients treated with cytotoxic chemotherapy alone and was not limited to first-line treatment; many patients had received conventional chemotherapy before immunotherapy. ${ }^{23}$

Previous retrospective studies have shown high AE-related costs among real-world patients with NSCLC ${ }^{16-18,23}$; however, the present study is the first to our knowledge to compare AE-related costs for NSCLC treatment with immuno-oncology agents versus conventional chemotherapy. We found that mean $\mathrm{AE}$ costs were significantly lower for the IO cohort than for the CHEM cohort, whether assessed as total costs $(\$ 13,887$ vs. $\$ 20,783 ; P<0.001)$ or PPPM ( $\$ 4,259$ vs. $\$ 6,323 ; P<0.001)$. Moreover, among patients who incurred $\mathrm{AE}$ costs, those in the IO cohort were $40 \%$ less likely to have high costs (defined as the 90th percentile) than those in the CHEM cohort. Given that larger proportions of high-cost versus lower-cost patients had inpatient stays, ICU admissions, and ED visits during the AE period, our findings suggest that high AE costs may have been driven by hospitalizations and ED visits, similar to what was seen in previous studies. , $, 3,16,18^{2}$

The lower prevalence rate ratios for ED visits and ICU admissions observed among high-cost versus lower-cost patients may have been due to the longer mean follow-up period in the highcost cohort. PPPM AE costs in our analysis were substantially higher than those in the only other similar U.S. real-world studies to date. Bittoni et al. (2018) and Arunachalam et al. (2018) found mean total PPPM AE-related costs of $\$ 1,084$ 
for first-line therapy and $\$ 1,036$ for second-line therapy, ${ }^{17,24}$ respectively. However, these earlier analyses were conducted in Medicare-only populations, included only costs related to AEs coded as the primary diagnosis on a claim, and adjusted costs to 2013 U.S. dollars, all of which likely contributed to this discrepancy.

We found that AE costs were not significantly different between the IO-CHEM and CHEM cohorts; this was unexpected, as the combination of therapies might be hypothesized to have a cumulative effect on AEs. The reasons for this finding cannot be determined with certainty from our data. However, given that our analysis did not account for chemotherapy strength or treatment duration, it may have been due to lower chemotherapy strength in the IO-CHEM cohort or to a longer follow-up period in the CHEM cohort (resulting in more time for AEs to be observed). In addition, it is possible that patients in the IO-CHEM cohort had been selected by their physicians as being more likely to tolerate combination therapy and therefore experienced fewer and/or less severe AEs.

Although the high cost of immuno-oncology agents has led to concerns regarding the potential economic burden of treatment with these drugs ${ }^{25}$ little research had been conducted until recently to elucidate the real-world costs involved. Our findings demonstrate that AE-related costs are actually lower among patients receiving IO treatment alone compared with conventional chemotherapy alone, and that AE costs are not substantially changed by the addition of IO treatment to chemotherapy. Interestingly, Korytowsky et al. (2018) found that total cost of care, hospitalizations, and ED visits were each significantly lower in the period after approval of IO treatment for NSCLC compared with the preapproval period. ${ }^{3}$ Taken together, the current evidence raises the possibility that IO treatment of patients with NSCLC could favorably affect total health care costs despite higher drug costs.

\section{Limitations}

This study faced several limitations. Certain variables that influence the choice of NSCLC therapy, such as performance status, were not available in the database; this may have resulted in unmeasured confounding. Mortality may have been underestimated as not all deaths are identified in claims or Social Security data. The IO cohort had a higher mean age than the other cohorts, suggesting that patients who are more frail may have been channeled to the IO cohort; however, the IO cohort was still less likely to experience AEs.

It was not possible to differentiate the cost of individual AEs for patients who had claims with codes for more than $1 \mathrm{AE}$. For these patients, costs were counted separately toward the total costs of both AEs, which may have caused slight overestimation of costs for some AEs. Overlap between infections and other AEs was particularly common, with $61.3 \%$ of patients hospitalized with infection also having evidence of another AE during the hospitalization. In a subanalysis, costs for hospitalizations that included both infection and another AE were higher than those for hospitalizations for either infection or the other AE independently (data not shown).

This study relied on diagnosis codes to identify mNSCLC and determine the presence of each AE; therefore, any coding errors may have resulted in misclassification of patients with NSCLC or AEs of interest, and medical claims may not have captured all AEs that occurred. Furthermore, because causality cannot be determined using claims data, the presence of a diagnosis code occurring after a cancer therapy does not guarantee that the associated condition was caused by the therapy. The effect of this limitation was minimized by looking for diagnosis codes for specific AEs known to be related to the therapies in our study.

Finally, because this analysis was conducted in a managed care population, the results may not be generalizable to other populations (e.g., patients who are uninsured).

\section{Conclusions}

Among real-world patients initiating nontargeted first-line therapy for mNSCLC, those receiving immunotherapy experienced fewer AEs and had lower total AE-related costs than those treated with cytotoxic chemotherapy. Furthermore, patients treated with immunotherapy were no more likely than patients treated with chemotherapy to incur AE-related costs and, in fact, were less likely to have high AE costs if they incurred any at all. These findings indicate that IO-related AEs are not a differentiating factor in cost of care for patients receiving first-line treatment for mNSCLC in clinical practice.

\section{Authors}

NICOLE M. ENGEL-NITZ, PhD; MICHAEL P. JOHNSON, MS; and SCOTT H. BUNNER, MPH, Optum, Eden Prairie, Minnesota. KELLIE J. RYAN, MPH, AstraZeneca, Gaithersburg, Maryland.

AUTHOR CORRESPONDENCE: Nicole Engel-Nitz, Optum, 11000 Optum Cir., MN101-E300, Eden Prairie, MN 55344. Tel.: 952.205.7770; E-mail: nicole.engel-nitz@optum.com.

\section{DISCLOSURES}

This study was sponsored by AstraZeneca. Ryan is an employee of AstraZeneca. Engel-Nitz, Johnson, and Bunner are employees of Optum, which was contracted by AstraZeneca to conduct this study, and shareholders in UnitedHealth Group. Engel-Nitz has also worked on cancer-related studies for which Optum received funding from Bayer AG, Clovis Oncology, Eli Lilly, EMD Serono, Exact Sciences, Janssen, and Novartis. Johnson worked on cancer-related studies for which Optum received funding from Eli Lilly, Medtronic, Sanofi, and UnitedHealthcare. Bunner has worked on cancerrelated studies for which Optum received funding from Celgene and Incyte. 


\section{ACKNOWLEDGMENTS}

Medical writing support, in accordance with Good Publication Practice (GPP3) guidelines, was provided by Yvette M. Edmonds, PhD, and Deja Scott Shemon, MPH, employees of Optum, and was funded by AstraZeneca. Randall Gerdes and Vincent Peichel programmed the analytic dataset with additional programming support from Yiyu Fang, PhD, and Feng (Felix) Cao, $\mathrm{PhD}$. Stacey Dacosta Byfield, PhD, of Optum, assisted in obtaining funding for this study. Jerry Seare, MD, and Shannon Reidt, PharmD, MPH, MSCR, aided in identifying relevant codes and medications for the study.

\section{REFERENCES}

1. American Cancer Society. Cancer facts \& figures 2019. 2019. Available at: https://www.cancer.org/content/dam/cancer-org/research/cancer-factsand-statistics/annual-cancer-facts-and-figures/2019/cancer-facts-and-figures-2019.pdf. Accessed April 27, 2020

2. National Cancer Institute. Financial burden of cancer care. March 2020. Available at: https://progressreport.cancer.gov/after/economic_burden. Accessed April 27, 2020

3. Korytowsky B, Radtchenko J, Nwokeji ED, Tuell KW, Kish JK, Feinberg BA. Understanding total cost of care in advanced non-small cell lung cancer pre- and postapproval of immuno-oncology therapies. Am J Manag Care. 2018;24(20 Suppl):S439-47.

4. National Cancer Institute. Non-small cell lung cancer treatment (PDQ)health professional version. March 2020. Available at: https://www.cancer. gov/types/lung/hp/non-small-cell-lung-treatment-pdq. Accessed April 27, 2020

5. Economopoulou P, Mountzios G. The emerging treatment landscape of advanced non-small cell lung cancer. Ann Transl Med. 2018;6(8):138.

6. Malhotra J, Jabbour SK, Aisner J. Current state of immunotherapy for non-small cell lung cancer. Transl Lung Cancer Res. 2017;6(2):196-211.

7. Hanna N, Johnson D, Temin S, Masters G. Systemic therapy for stage IV non-small-cell lung cancer: American Society of Clinical Oncology clinical practice guideline update. J Oncol Pract. 2017;13(12):832-37.

8. Brahmer J, Reckamp KL, Baas P, et al. Nivolumab versus docetaxel in advanced squamous-cell non-small-cell lung cancer. N Engl J Med. 2015;373(2):123-35.

9. Borghaei H, Paz-Ares L, Horn L, et al. Nivolumab versus docetaxel in advanced nonsquamous non-small-cell lung cancer. N Engl J Med. 2015;373(17):1627-39

10. Herbst RS, Baas P, Kim DW, et al. Pembrolizumab versus docetaxel for previously treated, PD-Ll-positive, advanced non-small-cell lung cancer (KEYNOTE-010): a randomised controlled trial. Lancet. 2016;387(10027):1540-50.

11. Fehrenbacher L, Spira A, Ballinger M, et al. Atezolizumab versus docetaxel for patients with previously treated non-small-cell lung cancer (POPLAR): a multicentre, open-label, phase 2 randomised controlled trial. Lancet. 2016;387(10030):1837-46.
12. Lemiale V, Meert AP, Vincent F, et al. Severe toxicity from checkpoint protein inhibitors: what intensive care physicians need to know? Ann Intensive Care. 2019;9(1):25

13. Polanski J, Jankowska-Polanska B, Rosinczuk J, Chabowski M, Szymanska-Chabowska A. Quality of life of patients with lung cancer. Onco Targets Ther. 2016;9:1023-28.

14. Nishijima TF, Shachar SS, Nyrop KA, Muss HB. Safety and tolerability of PD-1/PD-Ll inhibitors compared with chemotherapy in patients with advanced cancer: a meta-analysis. Oncologist. 2017;22(4):470-79.

15. Vardy J, Dadasovich R, Beale P, Boyer M, Clarke SJ. Eligibility of patients with advanced non-small cell lung cancer for phase III chemotherapy trials. BMC Cancer. 2009;9:130

16. Chouaid C, Loirat D, Clay E, et al. Cost analysis of adverse events associated with non-small cell lung cancer management in France. Clinicoecon Outcomes Res. 2017;9:443-49.

17. Bittoni MA, Arunachalam A, Li H, et al. Real-world treatment patterns, overall survival, and occurrence and costs of adverse events associated with first-line therapies for medicare patients 65 years and older with advanced non-small-cell lung cancer: a retrospective study. Clin Lung Cancer. 2018;19(5):e629-45

18. van der Linden N, Bongers ML, Coupe VM, et al. Costs of non-small cell lung cancer in the Netherlands. Lung Cancer. 2016;91:79-88.

19. National Comprehensive Cancer Network. Clinical practice guidelines in oncology. Non-small cell lung cancer, version 9.2018. Available at: https:// www.nccn.org/professionals/physician_gls/default.aspx. Accessed April 27, 2020.

20. Quan H, Li B, Couris CM, et al. Updating and validating the Charlson Comorbidity Index and score for risk adjustment in hospital discharge abstracts using data from 6 countries. Am J Epidemiol. 2011;173(6):676-82.

21. U.S. Department of Labor, Bureau of Labor Statistics. Consumer Price Index. Medical care. Series ID: SUUR0000SAM. 2017. Available at: https:// data.bls.gov/cgi-bin/surveymost?su. Accessed May 13, 2020

22. Fleishman JA, Cohen JW. Using information on clinical conditions to predict high-cost patients. Health Serv Res. 2010;45(2):532-52.

23. Cathcart-Rake EJ, Sangaralingham LR, Mansfield AS, et al Immunotherapy-related toxicities: more common than originally reported? J Clin Oncol. 2018;36(34 Suppl):184.

24. Arunachalam A, Li H, Bittoni MA, et al. Real-world treatment patterns, overall survival, and occurrence and costs of adverse events associated with second-line therapies for medicare patients with advanced non-small-cell lung cancer. Clin Lung Cancer. 2018;19(5):e783-99.

25. Tartari F, Santoni M, Burattini L, Mazzanti P, Onofri A, Berardi R. Economic sustainability of anti-PD-1 agents nivolumab and pembrolizumab in cancer patients: recent insights and future challenges. Cancer Treat Rev. 2016;48:20-24. 


\section{APPENDIX A Incidence of Selected AEs During the AE Period}

\begin{tabular}{|c|c|c|c|c|c|c|}
\hline \multirow[b]{2}{*}{ Event } & \multirow{2}{*}{$\begin{array}{c}\text { Total } \\
(\mathrm{N}=9,712)^{\mathrm{a}}\end{array}$} & \multirow{2}{*}{$\begin{array}{c}\text { CHEM } \\
(\mathbf{n}=8,818)^{\mathrm{a}}\end{array}$} & \multirow{2}{*}{$\begin{array}{c}\text { IO } \\
(\mathrm{n}=482)^{\mathrm{a}}\end{array}$} & \multirow{2}{*}{$\begin{array}{c}\text { IO-CHEM } \\
(\mathrm{n}=412)^{\mathrm{a}}\end{array}$} & \multicolumn{2}{|c|}{$P$ Value } \\
\hline & & & & & CHEM vs. IO & IO-CHEM vs. IO \\
\hline Any selected AE, \% & 74.4 & 75.2 & 64.9 & 69.2 & $<0.001$ & 0.003 \\
\hline Blood disorders ${ }^{\mathrm{b}}$ & 43.0 & 45.5 & 14.3 & 26.1 & $<0.001$ & $<0.001$ \\
\hline Gastrointestinal disorders & 31.6 & 32.4 & 20.3 & 27.1 & $<0.001$ & 0.028 \\
\hline Infections & 28.5 & 30.1 & 18.0 & 18.1 & $<0.001$ & 0.961 \\
\hline Anemia & 27.9 & 29.5 & 6.6 & 19.6 & $<0.001$ & $<0.001$ \\
\hline Infusion reactions & 26.3 & 26.0 & 29.3 & 29.6 & 0.117 & 0.907 \\
\hline Leukopenia & 17.1 & 18.6 & 1.0 & 4.6 & $<0.001$ & 0.001 \\
\hline Neurological disorders & 12.6 & 12.8 & 11.6 & 10.2 & 0.457 & 0.538 \\
\hline Hemorrhage & 10.7 & 11.0 & 8.8 & 6.5 & 0.150 & 0.235 \\
\hline Kidney injury & 8.9 & 8.9 & 8.4 & 8.4 & 0.688 & 0.981 \\
\hline Thrombocytopenia & 6.0 & 6.4 & 1.9 & 3.0 & $<0.001$ & 0.295 \\
\hline Hypothyroidism & 3.0 & 2.4 & 12.2 & 6.5 & $<0.001$ & 0.006 \\
\hline Pneumonitis & 2.4 & 2.4 & 3.2 & 2.8 & 0.228 & 0.703 \\
\hline Ocular disorders & 1.4 & 1.4 & 1.5 & 1.0 & 0.895 & 0.506 \\
\hline Hepatitis & 0.9 & 1.0 & 0.2 & 0.2 & 0.082 & 0.910 \\
\hline Type 1 diabetes & 0.8 & 0.8 & 0.6 & 0.8 & 0.710 & 0.831 \\
\hline Myositis & 0.7 & 0.7 & 0.2 & 0.0 & 0.188 & 0.355 \\
\hline Hyperthyroidism & 0.4 & 0.3 & 1.7 & 1.2 & $<0.001$ & 0.582 \\
\hline
\end{tabular}

APPENDIX B Population Mean Per Patient Per Month AE-Related Health Care Costs During the AE Period

\begin{tabular}{|c|c|c|c|c|c|c|}
\hline \multirow[b]{2}{*}{ Event } & \multirow{2}{*}{$\begin{array}{c}\text { Total } \\
(\mathrm{N}=9,712)\end{array}$} & \multirow{2}{*}{$\begin{array}{c}\text { CHEM } \\
(\mathrm{n}=8,818)\end{array}$} & \multirow{2}{*}{$\begin{array}{c}\mathrm{IO} \\
(\mathrm{n}=482)\end{array}$} & \multirow[b]{2}{*}{ IO-CHEM $(n=412)$} & \multicolumn{2}{|c|}{$P$ Value } \\
\hline & & & & & CHEM vs. IO & IO-CHEM vs. IO \\
\hline \multicolumn{7}{|l|}{ Any selected AE } \\
\hline $\mathrm{n}$ & 7,135 & 6,543 & 309 & 283 & & \\
\hline Total follow-up months & 41,467 & 38,111 & 1,959 & 1,398 & & \\
\hline Cost PPPM & 3,880 & 3,950 & 2,574 & 3,808 & $<0.001$ & 0.010 \\
\hline U.S. \$ (95\% CI) & $(3,719-4,042)$ & $(3,779-4,121)$ & $(1,991-3,156)$ & $(3,082-4,534)$ & & \\
\hline \multicolumn{7}{|l|}{ Blood disorders ${ }^{\mathrm{a}}$} \\
\hline $\mathrm{n}$ & 3,071 & 2,933 & 53 & 85 & & \\
\hline Total follow-up months & 18,528 & 17,762 & 371 & 395 & & \\
\hline Cost PPPM & 2,779 & 2,794 & 1,360 & 3,427 & $<0.001$ & 0.011 \\
\hline U.S. \$ $(95 \%$ CI $)$ & $(2,568-2,990)$ & $(2,577-3,011)$ & $(777-1,943)$ & $(1,971-4,882)$ & & \\
\hline \multicolumn{7}{|l|}{ Anemia } \\
\hline $\mathrm{n}$ & 2,175 & 2,077 & 28 & 70 & & \\
\hline Total follow-up months & 12,956 & 12,419 & 201 & 337 & & \\
\hline Cost PPPM & 2,764 & 2,769 & 1,594 & 3,254 & 0.011 & 0.071 \\
\hline U.S. \$ (95\% CI) & $(2,504-3,024)$ & $(2,502-3,036)$ & $(732-2,456)$ & $(1,712-4,797)$ & & \\
\hline \multicolumn{7}{|l|}{ Infusion reactions } \\
\hline $\mathrm{n}$ & 2,529 & 2,268 & 140 & 121 & & \\
\hline Total follow-up, months & 15,961 & 14,264 & 1,013 & 684 & & \\
\hline Cost PPPM & 2,846 & 2,969 & 1,334 & 2,527 & $<0.001$ & 0.018 \\
\hline U.S. \$ (95\% CI) & $(2,604-3,089)$ & $(2,704-3,234)$ & $(715-1,954)$ & $1,770-3,285)$ & & \\
\hline \multicolumn{7}{|l|}{ Gastrointestinal disorders } \\
\hline $\mathrm{n}$ & 2,522 & 2,349 & 77 & 96 & & \\
\hline Total follow-up months & 15,430 & 14,369 & 564 & 497 & & \\
\hline Cost PPPM & 1,641 & 1,661 & 1,189 & 1,580 & 0.206 & 0.434 \\
\hline U.S. \$ (95\% CI) & $(1,475-1,808)$ & $(1,486-1,836)$ & $(479-1,900)$ & $(917-2,244)$ & & \\
\hline
\end{tabular}




\section{APPENDIX B Population Mean Per Patient Per Month AE-Related Health Care Costs} During the AE Period (continued)

\begin{tabular}{|c|c|c|c|c|c|c|}
\hline \multirow[b]{2}{*}{ Event } & \multirow{2}{*}{$\begin{array}{c}\text { Total } \\
(\mathrm{N}=9,712)\end{array}$} & \multirow{2}{*}{$\begin{array}{c}\text { CHEM } \\
(n=8,818)\end{array}$} & \multirow{2}{*}{$\begin{array}{c}\mathrm{IO} \\
(\mathrm{n}=482)\end{array}$} & \multirow[b]{2}{*}{ IO-CHEM $(n=412)$} & \multicolumn{2}{|c|}{$P$ Value } \\
\hline & & & & & CHEM vs. IO & IO-CHEM vs. IO \\
\hline \multicolumn{7}{|l|}{ Infections } \\
\hline $\mathrm{n}$ & 1,676 & 1,537 & 75 & 64 & & \\
\hline Total follow-up months & 9,951 & 9,222 & 467 & 262 & & \\
\hline Cost PPPM & 3,799 & 3,764 & 3,334 & 5,852 & 0.470 & 0.032 \\
\hline U.S. \$ (95\% CI) & $(3,449-4,149)$ & $(3,396-4,133)$ & $(2,226-4,443)$ & $(3,876-7,828)$ & & \\
\hline \multicolumn{7}{|l|}{ Leukopenia } \\
\hline $\mathrm{n}$ & 1,596 & 1,573 & 4 & 19 & & \\
\hline Total follow-up months & 9,427 & 9,317 & 23 & 87 & & \\
\hline Cost PPPM & 2,276 & 2,274 & 859 & 2,947 & 0.039 & 0.168 \\
\hline U.S. \$ (95\% CI) & $(2,042-2,511)$ & $(2,037-2,510)$ & $(-464$ to 2,182$)$ & $(540-5,354)$ & & \\
\hline \multicolumn{7}{|l|}{ Neurological disorders } \\
\hline $\mathrm{n}$ & 1,071 & 985 & 48 & 38 & & \\
\hline Total follow-up months & 7,035 & 6,497 & 351 & 187 & & \\
\hline Cost PPPM & 2,547 & 2,594 & 987 & 3,848 & $<0.001$ & 0.017 \\
\hline U.S. \$ (95\% CI) & $(2,108-2,986)$ & $(2,124-3,063)$ & $(514-1,459)$ & $(1,613-6,082)$ & & \\
\hline \multicolumn{7}{|l|}{ Hemorrhage } \\
\hline $\mathrm{n}$ & 888 & 827 & 37 & 24 & & \\
\hline Total follow-up months & 5,804 & 5,433 & 270 & 101 & & \\
\hline Cost PPPM & 2,849 & 2,885 & 1,729 & 3,915 & 0.043 & 0.229 \\
\hline U.S. \$ (95\% CI) & $(2,403-3,296)$ & $(2,416-3,355)$ & $(716-2,743)$ & $(591-7,240)$ & & \\
\hline \multicolumn{7}{|l|}{ Kidney injury } \\
\hline $\mathrm{n}$ & 773 & 706 & 35 & 32 & & \\
\hline Total follow-up months & 4,818 & 4,436 & 237 & 146 & & \\
\hline Cost PPPM & 3,529 & 3,574 & 2,092 & 4,501 & 0.024 & 0.094 \\
\hline U.S. \$ (95\% CI) & $(3,023-4,035)$ & $(3,034-4,113)$ & $(928-3,256)$ & $(2,018-6,985)$ & & \\
\hline \multicolumn{7}{|l|}{ Thrombocytopenia } \\
\hline $\mathrm{n}$ & 563 & 543 & 8 & 12 & & \\
\hline Total follow-up months & 3,671 & 3,567 & 32 & 72 & & \\
\hline Cost PPPM & 1,982 & 1,977 & 5,316 & 772 & 0.313 & 0.216 \\
\hline U.S. \$ (95\% CI) & $(1,521-2,443)$ & $(1,507-2,447)$ & (-1,156 to 11,788$)$ & (-583 to 2,128$)$ & & \\
\hline \multicolumn{7}{|l|}{ Hypothyroidism } \\
\hline $\mathrm{n}$ & 269 & 192 & 53 & 24 & & \\
\hline Total follow-up months & 2,259 & 1,606 & 466 & 188 & & \\
\hline Cost PPPM & 533 & 564 & 379 & 654 & 0.288 & 0.610 \\
\hline U.S. \$ (95\% CI) & $(337-729)$ & $(324-804)$ & $(138-620)$ & $(-362$ to 1,670$)$ & & \\
\hline \multicolumn{7}{|l|}{ Pneumonitis } \\
\hline $\mathrm{n}$ & 221 & 196 & 14 & 11 & & \\
\hline Total follow-up months & 1,510 & 1,307 & 131 & 72 & & \\
\hline Cost PPPM & 2,906 & 3,045 & 1,241 & 3,408 & 0.004 & 0.201 \\
\hline U.S. \$ $(95 \%$ CI) & $(2,097-3,716)$ & $(2,133-3,957)$ & $(436-2,045)$ & $(399-6,417)$ & & \\
\hline \multicolumn{7}{|c|}{$\begin{array}{l}\text { Note: Population cost estimates represent total AE-related costs divided by the total person-time during the AE period. AEs occurring in }>2 \% \text { of patients are shown, listed } \\
\text { in order of incidence rate from highest (any selected AE) to lowest (pneumonitis). Costs presented are among patients without the selected AE during the variable baseline } \\
\text { period, and exclude zero costs. } \\
\text { aIncludes anemia, leukopenia, and thrombocytopenia. } \\
\text { AE= adverse event; CHEM = cytotoxic chemotherapy; CI = confidence interval; IO =immuno-oncology agents; IO-CHEM=immuno-oncology + cytotoxic chemotherapy; } \\
\text { PPPM = per patient per month. }\end{array}$} \\
\hline
\end{tabular}

